TITLE:

\title{
The Kinetics of the Decompositions of Ethylene-Mercuric Salt Addition Compounds with Hydrochloric Acid
}

\section{$\operatorname{AUTHOR(S):~}$}

Ichikawa, Katsuhiko; Ouchi, Hajime; Araki, Shigemitsu

\section{CITATION:}

Ichikawa, Katsuhiko ...[et al]. The Kinetics of the Decompositions of Ethylene-Mercuric Salt Addition Compounds with Hydrochloric Acid. Bulletin of the Institute for Chemical Research, Kyoto University 1961, 39(3): 253-254

\section{ISSUE DATE:}

1961-07-31

URL:

http://hdl.handle.net/2433/75824

RIGHT: 
The Kinetics of the Demercuration Reaction of Benzyl-

and $\beta$-( $p$-Methoxyphenyl)-ethyl-mercuric

Acetate with Perchloric Acid

Katsuhiko IchikAw a and Hajime Ouchr

J. Am. Chem. Soc., 82, 3876 (1960)

To clarify the mechanism of the final steps involved in the reactions of olefinmercuric acetate addition compounds with aromatics to form $\beta$-arylethyl acetates (cf. J. Am. Chem. Soc., 80, 6005 (1958); 81, 3401 (1959)), the kinetics of the demercuration reaction of benzyl-and $\beta$-( $p$-methoxyphenyl)-ethyl-mercuric acetate (one of the intermediate mercurials) have been studied. In aqueous acetic acid solutions containing perchloric acid, rate expressions were eatablished for the second-order reaction 1 and first-order reaction 2 .

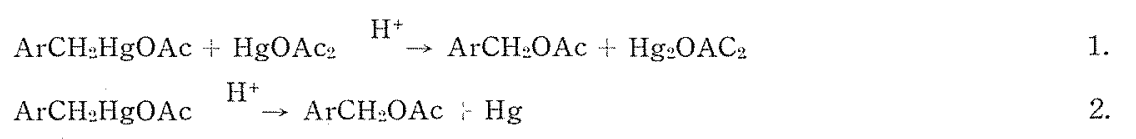

Perchloric acid concentrations affected the rates of both reactions remarkably. Possible mechanisms are proposed below. For reaction 1 ,

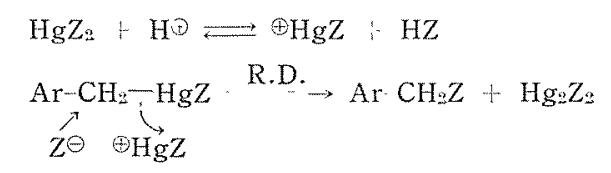

For reaction 2 ,

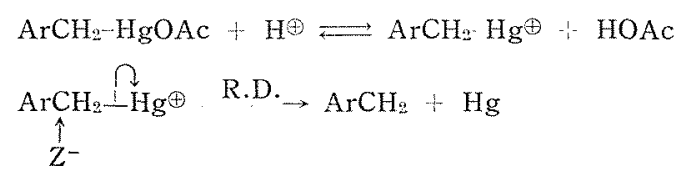

The Kinetics of the Decompositions of Ethylene-Mercuric Salt Addition Compounds with Hydrochloric Acid

Katsuhiko Ichikawa, Hajime Ouchi and Shigemitsu AraKI

J. Am. Chem. Soc., 82, $3880(1960)$

The kinetics of decompositions of ethylene-mercuric salt addition compounds with hydrochloric acid $\left(\mathrm{ROCH}_{2} \mathrm{CH}_{2} \mathrm{HgCl}+\mathrm{HCl}=\mathrm{CH}_{2} \mathrm{CH}_{2}+\mathrm{HgCl}_{2}+\mathrm{ROH}\right)$ has been studied in water-ethanol mixtures and found to be third order (first order in addition compounds, hydronium ion and chloride ion, respectively). Selected values of the kinetic data are shown in the table below. 


$\begin{array}{lccc}\mathrm{R} & \mathrm{k}_{3} \cdot 10^{2} \text { at } 0^{\circ} \mathrm{HCl}, 0.1614 M & \text { Eact. kcal./mole } & \log \mathrm{PZ} \\ 75 \% \text { ethanol. } & 18.8 & 11.9 \\ \mathrm{Ac}- & 0.0789 & 20.0 & 13.2 \\ \mathrm{Me}- & .163 & 20.2 & 13.4 \\ \mathrm{Et}- & .176 & 19.4 & 13.0 \\ i-\operatorname{Pr}- & .290 & 18.4 & 12.8 \\ \mathrm{H}- & 1.33 & \end{array}$

The effects of the compositions of the solvent and the concentrations of hydrochloric acid on the rates have been explained in term of the activities of the acid. In the presence of perchloric acid, it has been demonstrated that $\mathrm{R}$ in the addition compound can be replaced by the solvent without decomposition. On the basis of these observations, the following mechanism is proposed:

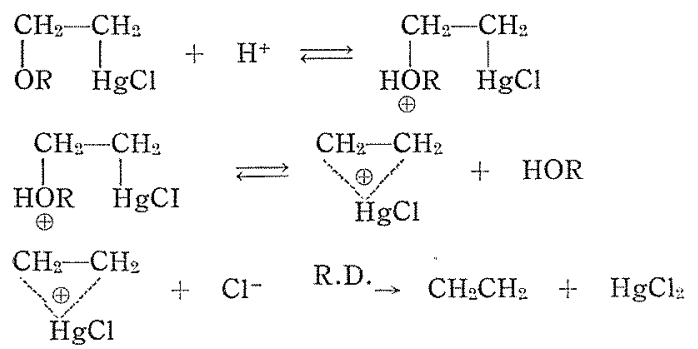

A Novel Synthesis of $\alpha$-Methylmuconic Acid

Shuji Inamasu, Yuzo Inouye and Minoru Ohno

Botyu-Kagaku (Chemistry of Insect Control), 25, 108 (1960)

$o$-Methylcatechol was prepared from o-cresol through 3-nitro-o-cresol, 3-nitro2-methoxy-toluene, 3-amino-2-methoxy-toluene and 3-hdroxy-2-methoxy-toluene. Peracetic acid oxidation of $\alpha$-methylcatechol afforded $\alpha$-methyl-cis,cis-muconic acid in a higher yield than that obtained by direct peracid oxidation of $o$-cresol.

\section{Blätteraldehyd: Eine einfache Synthese und Konfiguration}

Akikazu Hatanaka and Minoru Ohno

Bull. Agr. Chem. Soc. Japan, 24, 532 (1960)

Blätteraldehyd wurde durch die einfachste, ergiebigste Synthese dargestellt. Demnach wurde es aufgeklärt, dass die Konfiguration des natürlichen Blätteraldehyds trans-Form ist. 